\title{
Review Article \\ Phacoemulsification and Intraocular Lens Implantation: Recent Trends in Cataract Surgery
}

\author{
H. KECOVÁ, A. NEČAS
}

Department of Surgery and Orthopaedics, Small Animal Clinic, Faculty of Veterinary Medicine, University of Veterinary and Pharmaceutical Sciences, Brno, Czech Republic

$$
\text { Received November 11, } 2003
$$

Accepted February 11, 2004

\section{Abstract}

Kecová, H., A. Nečas: Phacoemulsification and Intraocular Lens Implantation: Recent Trends in Cataract Surgery. Acta Vet. Brno 2004, 73: 85-92.

This review article summarizes the evolution of cataract surgery techniques and intraocular lens (IOL) implantation. It emphasizes the necessity of appropriate patient selection for the surgery and precise surgical technique for successful outcome of this procedure in dogs. The history of cataract surgery, factors critical for good outcome of the procedure, timing of surgery, preoperative medication, phacoemulsification technique and types of implanted intraocular lenses are discussed.

Cataract, phacoemulsification, intraocular lens, dog

Cataract (Plate XIII, Fig. 1) is a leading cause of unilateral and more often bilateral blindness in dogs. The only effective mean of its treatment is surgery - extraction of diseased lens (Dziezyc 1990) and its replacement by an artificial intraocular lens (IOL = "intraocular lens"). The opinions on cataract surgery have been changing continually with advancement of the procedure. The success rate of cataract surgery has risen significantly during last decades, especially thanks to development of more precise microsurgical techniques and with introduction of phacoemulsification (Boldy 1988; Dziezy c 1990) and IOL implantation.

\section{History of cataract surgery}

The initiation of "cataract surgery" is mentioned in ancient India as early as 2000 years B.C.; at that time the only attempt was to restore vision by iatrogenic posterior luxation of cataractous lens - reclination. Until now reclination remains a method of choice of shamans in some parts of Africa (Ghana).

In 1745 Daviel performed the first extracapsular cataract extraction (ECCE). In 1753 Sharp performed the first intracapsular cataract extraction (ICCE) by expression of the nucleus using a thumb. During the 17th, 19th and the beginning of 20th century, the most popular method of cataract extraction was ICCE (different methods of mechanical zonulolysis). After the 2nd World War, the ECCE became more popular with development of better operating microscopes. In 1949 Harold Ridley implanted first posterior chamber IOL in a 60-year-old woman after previous ECCE (Ridley 1952). However, due to a large degree of secondary cataract, glaucoma and anterior chamber inflammation following "primitive" ECCE (without irrigation/aspiration of remaining cortical material), this method was again replaced by intracapsular extraction. In 1957, Barraquer carried out the first ICCE using enzymatic zonulolysis (B arraquer 1958) and in 1961 first cryoextraction was done by Krawicz. In 1970s, with improved irrigation/aspiration devices and capsulotomy techniques, surgeons again returned to ECCE (now with complete removal of remaining cortical material). With the development of ultrasound machines creating low

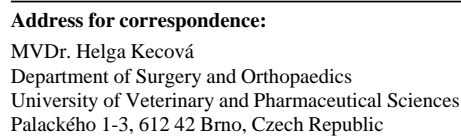

Phone: +420606321 211

Fax. +420541562344

E-mail: hkecov@ hotmail.com

th://www.vfu.cz/acta-vet/actavet htm 
frequency ultrasound waves, in 1967 Kelman carried out first so called "phacoemulsification" of the lens, or ECCE using phacoemulsification (Kelman 1967). Removal of the nucleus through a small incision pushed research in development of new machines as well as artificial IOLs. Since then the progress is in introducing of viscoelastics (protection of intraocular structures, facilitation of manipulation in the eye) (Craig 1990; Artola 1993), development of more sophisticated technical equipment, miniaturization of the instruments and in improvement of IOL material (Linebarger et al. 1999).

In early days of cataract surgery in veterinary medicine the ICCE method was used mechanical or enzymatic zonulolysis with chymotrypsin (Startup 1967; Barrie et al. 1982). The advantage of this method consisted in removing lens with the capsule, without deliberating of any of its material within the eye. The disadvantages are anterior displacement of the vitreous with the risk of retinal detachment (Dziezyc 1990) and, as in all nonminiinvasive methods, the size of incision (approximately $190^{\circ}$ of limbal circumference, or 20-22 $\mathrm{mm}$ ) resulting in large extent of astigmatism and marked inflammatory and fibrin reaction with subsequent complications. The next method, in veterinary medicine used for a long time, was ECCE (Startup 1967; Rooks et al. 1985; Paulsen et al. 1986). The main disadvantages are the size of incision and the need of progression of cataract (surgery at the time of mature cataract). With the progression of cataract, the phacolytic uveitis develops and with no visible tapetal reflection it can be quite difficult to visualize the anterior capsule during capsulotomy. Nowadays, even in veterinary medicine, the method of choice in most cases is phacoemulsification, or removal of lens material through small incision with fragmentation, emulsification and aspiration (Miller et al. 1987; Gaiddon et al. 1988; Dziezyc 1990; Nasisse et al. 1990; Davidson et al. 1991; Nelms et al. 1994; Gilger 1997). The only disadvantages are the cost and learning curve of this procedure.

Phacoemulsification

For the good outcome of surgery are critical:

1) selection of the patient

2) surgical technique

3) perioperative screening and therapy

Adequate history of the case and general examination should be done in all patients to reveal systemic diseases accompanied by cataract (e.g., diabetes), discover any underlying ocular (Vlková et al. 1991) or systemic disease, that would affect the surgery or anesthesia protocol, and exclude extremely hyperactive or aggressive patients from the surgery (in such patients the post-operative rest, treatment and check-ups might be impossible). Preoperative examination should include complete ophthalmologic exam. Intraocular pressures (IOP) are taken to check for underlying glaucoma/uveitis (Hlinomazová and Vlková 2003; Vlková and Hlinomazová 2003). Thorough slit lamp examination/biomicroscopy should reveal any visual interference in cornea (opacity, edema, pigmentation) or anterior lens capsule [plaques suggest possible similar changes on the posterior capsule $-\mathrm{Na}$ sis se and Davidson (1991)] and the state of suspensory apparatus of the lens (signs of lens sub-/luxation). Thorough fundoscopy should be done, if possible, to exclude any abnormalities such as retinal detachment or progressive retinal atrophy (PRA). Especially in cases where fundus is not visible through the lens, the ERG examination is advisable (especially in breeds with predisposition to PRA). USG examination can reveal retinal detachment and vitreal degeneration or hemorrhages (Van der Woerdt et al. 1993).

Timing of the surgery

As opposed to ECCE (surgery at the stage of mature cataract), phacoemulsification should be done as soon as possible. There are several reports on worse prognosis with the surgery 
at the time of mature/hypermature cataract (Fischer 1972; Paulsen et al. 1986; V an der Woerd t et al. 1992) due to phacolytic uveitis, plaques on posterior capsule and/or zonular instability. Another controversial question is whether to operate both eyes at the same time or perform two separate surgeries; each of these has both advantages and disadvantages (Davidson et al. 1990).

Preoperative medication

There are numbers of different protocols used prior to cataract surgery (Dziezyc et al. 1989; Dziezyc 1990; Williams et al. 1996; Nasisse and Davidson 1991), the selection depending on the surgeon's preference, type of surgery performed and, according to West (in Williams et al. 1996), even on specific reactivity of patients in different regions. However, most protocols are aiming at three targets: suppression of inflammation (topical steroids and/or NSAIDs several days/hours ahead of surgery), elimination of infection (broad spectrum antibiotics several hours to days prior to surgery) and inducing mydriasis (topical atropin or tropicamide several hours prior the surgery, or intracameral application of adrenalin at the time of surgery - Peterson-Jones and Clutton (in Williams et al. 1996)). Most surgeons also use single intravenous application of flunixin meglumine at the time of induction of anesthesia.

\section{Anesthesia}

In human medicine most uncomplicated cases are operated in local anesthesia (Atkin s on 1948; Bloomberg 1986; Bloomberg 1991; Fichman 1996), the complicated cases in general anesthesia - systemic neuromuscular blocking (Davis 1994). In veterinary medicine general anesthesia is evidently imperative. Most surgeons prefer systemic neuromuscular blocking agents, because it markedly simplifies the procedure by eliminating bulbar rotation (Dziezyc 1990; Nasisse and Davidson 1991).

\section{Incision}

There are three possibilities for access to the lens: clear corneal, limbal or scleral-based approach. Comparison of these was published (Nelms et al. 1994). In dogs the lens is most easily accessed by clear corneal incision, which is also the easiest to create; on the other hand it leads to greater degree of astigmatism and fibrosis and it is more critical to precisely appose wound edges to achieve water tightness. Posteriorly placed incisions induce lesser astigmatism, heal faster with less fibrosis, but are more difficult to create and what is more important, there is more chance to touch the iris and much higher tendency to iris prolaps. Also the access to the lens, especially the part closest to surgeon (mostly 12 o'clock position) is complicated. Last, but not least complication of such incisions is bleeding from sclera, which can result in more complications (Nelms et al. 1994; Nasisse and Davidson 1991).

Size of incision depends on the method used. Opposed to ECCE $\left(190^{\circ}\right.$ of limbal circumference, or approximately 20-22 mm), standard incision for phaco is $3.2 \mathrm{~mm}$, which is in case of implantation of PMMA lens widened to $8 \mathrm{~mm}$ (Nasisse and Davidson 1990), in case of foldable IOL to $4.2 \mathrm{~mm}$ (Gaidd on et al. 1997, author's own experience), with injector even smaller $(3.8 \mathrm{~mm})$. With bimanual technique, one side port, approximately $1 \mathrm{~mm}$ wide, oriented toward the surgeon's non-dominant hand is created in limbus.

\section{Capsulotomy}

Provided with different instruments (cystotome, hypodermic needle, Vanas scissors, capsulorhexis forceps), the most common method being continuous curvilinear capsulorhexis (Gimbel and Neuhman 1990). For ideal stability of IOL the capsulorhexis should be circular, with diameter $1 \mathrm{~mm}$ smaller than the optic part of IOL (Nasisse and Davidson 1991). 
Hydrodissection

Hydrodissection enables division of the lens material from the capsule using application of solution between the capsule and the lens through $27 \mathrm{G}$ cannula. In some cases (onehanded techniques, hard cataracts) it can be useful to perform hydrodissection after sculpting the nucleus (excluding free movements of nucleus) (Nasisse and Davidson 1991). In some bimanual techniques, especially in cases of hard nuclei, hydrodelineation (separation of different levels of the lens nucleus) is also used.

Phacoemulsification technique

The principle of phaco is to sculpt and fragment the nucleus and subsequently remove it by aspiration and aspirate all remaining cortical material (Plate XIII, Fig. 2) (Kelman 1994; Nasisse and Davidson 1991). During last three decades plenty of techniques have been developing. The main regimentation would be one-handed versus bimanual techniques, anterior versus posterior fragmentation and fragmentation after completing of capsulorhexis versus before capsulorhexis (intracapsular).

One-handed technique has the advantage in the possibility of using the non-dominant hand for manipulation with the globe and it is easier to learn. On the other hand it is more complicated to reach all parts of the lens (especially the part closest to the surgeon, most commonly the 12 o'clock position). It also necessitates manipulation close to the posterior capsule. With bimanual techniques the surgeon uses his second hand to manipulate the nucleus with special intraocular instrument through the side port. This is particularly useful with the hard canine nuclei, where it enables manipulation far from the posterior capsule. The second instrument can also help to push hard fragments towards and into the phaco needle. The main disadvantage of this technique is the risk of posterior capsule perforation with the second instrument and longer time to master it.

Phacoemulsification in the anterior chamber increases the risk of corneal endothelium damage. That is why it should be performed exclusively within the lens capsule (posterior chamber phacoemulsification). Attempts to protect the endothelium even further led to development of endocapsular techniques, or phacofragmentation and aspiration through a small incision in the anterior capsule and finishing the capsulorhexis afterwards (Obstbaum 1987; Gaiddon et al. 1988).

One of the most safe and towards intraocular structures most gentle methods is nucleofraction. The first to refer on this method was Kelman, but he was working in the anterior chamber. Gimbel's "divide and conquer" (Gimbel 1991) is considered to be the basic technique using nucleofraction. This bimanual technique was modified by Shepherd who was the first to divide the nucleus in a cross manner (Shepherd 1990). In 1993 Nagahara introduced a new technique of phacofragmentation, "phaco chop" (in McKool 1998). In 1996 Pfeiffer published the next modification, "phaco-crack". Maloney's supracapsular phacoemulsification is a different method that enables to shorten the phaco time by half (Fine 1993). Besides these main techniques, there is a plenty of different modifications. In the dog, due to a harder nucleus compared to humans, surgeons usually use combinations of mentioned methods.

Irrigation/aspiration

After emulsification of the nucleus, it is necessary to remove all remaining cortical material to avoid post-surgical complications (Nasisse and Davidson 1991). One can use either bimanual, or one-handed irrigation/aspiration (I/A), the latter being the method of choice for most surgeons. After I/A, the posterior capsule is polished with I/A tip (set to very low vacuum) or with different types of capsule polishers.

Types of IOLs

IOLs serve as optimal correction of aphakia. Harold Ridley started modern implantology era in 1949, when he implanted the first polymethylmetacrylate (PMMA) posterior chamber 
IOL (Ridley 1952). In our country this type of lens was firstly implanted by Vanýsek in 1954 (Vlková et al. 1991). Further evolution headed towards anterior chamber lenses; first prototype was implanted by Strampelli in 1951 (Linebarger et al. 1999). The next landmark is the introduction of the iris-supported lens by Binkhorst (Binkhorst et al. 1972). Since the year 1949 the dominant material has been PMMA, since 1984 starts the development of soft, foldable IOLs (Mazzocco 1984).

Materials of intraocular lenses

The important characteristics of IOLs are: density, refractive index, optical transmittance, dimensional stability, mechanical properties, biocompatibility, toxicity and chemical stability.

\section{Thermoplastics}

PMMA - polymethylmetacrylate is a polymer of methylmetacrylate monomer. It is light, durable, has refractive index 1.49. It is well tolerated, although it is not totally inert material. PMMA lenses are rigid; implantation is completed through a 6-8 $\mathrm{mm}$ incision.

\section{Synthetic elastomers}

Silicon is biocompatible flexible and elastic material with refractive index of 1.41-1.46. One of the disadvantages of silicon lenses is that they get damaged in contact with silicon oil (condensation in the lens); that is why they should not be used in patients with possibility of future need of vitreoretinal surgery (e.g., patients with diabetes).

\section{Acrylate polymers}

Hydrogel and hybrid hydrogel lenses (Barrett 1991; Barrett 1994). The basis of all hydrogel polymers is acrylic hydrophilic monomer HEMA with a refraction index 1.431.48. Individual lenses differ in material composition and amount of water. One of the besttolerated lenses is monoblock (it is made out of 1 piece), with low content of water; in 16$18 \%$ there is an occurrence of minute posterior capsule opacification (PCO).

Soft acrylic IOLs (Oshica 1996). It is hydrophobic lens with refractive index 1.47-1.55. It is biocompatible, foldable, with minimal occurrence of PCO.

Collamer IOLs. Brand-new material is the combination of silicon and collagen. This material is used for cataract as well as for refractive surgeries, due to its high refractive index and excellent biocompatibility. These lenses are very thin, thus allowing implantation through incision even smaller than $3.2 \mathrm{~mm}$.

Soft lenses - after introduction of phacoemulsification, the research was directed to invention of foldable lenses (Kohnen 1996), which would allow implantation through small incisions, thus minimizing astigmatism and post-surgery complications (e.g., fibrin reaction, infection). The most common materials are silicon elastomers and acrylate/metacrylate polymers. The implantation of soft lenses is achieved through 3.2-4 $\mathrm{mm}$ incision, depending on the size of the lens and the way of implantation (forceps, injector).

IOLs in dogs

Although there have been many discussions whether to implant IOLs in dogs or not (Bigelbach 1994), at present time most surgeons tend to implant (Nasisse et al. 1990; Davidson et al. 1991; Gaiddon et al. 1991; Gilger et al. 1993; Nelms et al. 1994; Gaidd on et al. 1997). There are two main types of IOLs used in veterinary medicine - hard (PMMA - Gilger et al. 1993) and foldables - silicon (Gilger et al. 1993; Gaiddon et al. 1997) and acrylic polymers (Plate XIII, Fig. 3) (author's experience; Rosolen, personal communication, 2004). The lenses are implanted within the capsular bag; the anterior chamber and iris-supported lenses are not used due to high extend of complications ( $\mathrm{Nasisse}$ and 
Davidson 1991). The optic power is most commonly 41D (Gaiddon et al. 1991), the sizes differ from 14 to $18 \mathrm{~mm}$ (haptic size), with $7 \mathrm{~mm}$ optic.

Most implanted lenses in dogs are PMMA, although recently many surgeons tends to use soft, foldable lenses. Gaiddon et al. described use of silicon lens in 1997 (Gaiddon et al. 1997). The latest type of soft lenses designed for dogs are made of hydrophilic acrylate. The unquestionable advantage of acrylic lenses is the size of incision as well as the excellent biocompatibility. On the other hand, in the cases of implantation in the capsule of subluxated lenses or where the posterior circular capsulorhexis is necessary due to fibrosis, the PMMA lenses may be unreplaceable.

Owing to better equipment and more precise, microsurgical methods, the success rate of cataract extraction in dogs has raised significantly. Thanks to introducing new, foldable materials there is a possibility of faster postoperative rehabilitation of patients together with minimal intraoperative damage of ocular tissues. The future will reveal all advantages and differences between hard and soft IOLs implanted in dogs. Regardless of which type of lens is implanted, if we fulfill all necessary criteria for good outcome (selection of the patient, correct surgical technique, adequate equipment) we can successfully treat this common disease of dogs.

\section{Fakoemulzifikace a implantace nitroočních čoček: současný trend v chirurgii katarakt}

Tento článek podává přehled o vývoji chirurgických technik v operaci katarakty a vývoji implantace nitroočních čoček. Vyzdvihuje nezbytnost precizní chirurgické techniky ale i výběru vhodného pacienta pro dosažení dobrých výsledků při tomto zákroku u psů. Jsou zde diskutovány faktory nezbytné pro dobrý výsledek operace, ale i vhodné načasování zákroku, perioperační medikace, techniky fakoemulzifikace a typy $\mathrm{v}$ současnosti používaných nitroočních čoček.

\section{Acknowledgements}

This work was supported by the Ministry of Education, Youth and Sports of the Czech Republic (Research Project No. 161700002). The authors thank to Alcon Pharmaceuticals (Czech Republic) s.r.o. for technical support while gaining our own experience with phacoemulsification in dogs.

\section{References}

ARTOLA, A, ALIO, JL, BELLOT, JL, RUIZ, JM 1993: Protective properties of viscoelastic substances (sodium hyaluronate and $2 \%$ hydroxymethylcellulose) against experimental free radical damage to the corneal endothelium. Cornea 12: 109-114

ATKINSON, WS 1948: Local anesthesia in ophthalmology. Am J Ophthalmol 31: 1607-1618

BARRAQUER, J 1958: Enzymatic zonulolysis: contribution to surgery of the lens. Surv Ophthalmology 3: 299-303

BARRETT, GD 1991: The evolution of hydrogel implants. Dev Ophthalmol 22: 70-71

BARRETT, GD 1994: A new hydrogel intraocular lens design. J Cataract Refract Surg 20: 18-25

BARRIE, KP, GELATT, KN, GUM, GG, SAMUELSON, DA 1982: Effects of alpha chymotrypsin on the canine eye. Am J Vet Res 43: 207-216

BIGELBACH, A 1994: For and against lens implantation in dogs. Veterinary Quarterly 16 (Suppl. 1): 58S-59S

BINKHORST, CD, KATZ, A, LEONARD, PAM 1972: Extracapsular pseudophakia results in 100 two loop iridocapsular lens implantations. Am J Ophthalmol 73:625-636

BLOOMBERG, LB 1986: Administration of periocular anesthesia. J Cataract Refract Surg 12: 677-679

BLOOMBERG, LB 1991: Anterior periocular anesthesia: five years experience. J Cataract Refract Surg 17: 508-511

BOLDY, KL 1988: Current status of canine cataract surgery. Semin Vet Med Surg (Small Anim) 3: 62-68

CRAIG, MT, OLSON, RJ, MAMALIS, N, OLSON, RJ 1990: Air bubble endothelial damage during phacoemulsification in human eye bank eyes: the protective effects of Healon and Viscoat. J Cataract Refract Surg 16: 597-602

DAVIDSON, MG, NASISSE, MP, JAMIESON, VE, ENGLISH, RV, OLIVERO, DK 1991: Phacoemulsification and intraocular lens implantation: a study of surgical results in 158 dogs. Prog Vet Comp Ophthalmol 1: 233-238 
DAVIDSON, MG, NASISSE, MP, RUSNAK, IM, CORBET, WT, ENGLISH, RV 1990: Success rates of unilateral vs. bilateral cataract extraction in dogs. Vet Surg 19: 232-236

DAVIS, DB, MANDEL, MR 1994: Anesthesia for cataract extraction. Int Ophthalmol Clin 34: 13-33

DZIEZYC, J 1990: Cataract surgery, current approaches. Vet Clin North Am: Small Anim Pract 20: 737-754

DZIEZYC, J, MILLICHAMP, NJ, ROHDE, BH, BAKER, JS, CHIOU, GC 1989: Effects of lipoxygenase inhibitors in a model of lens-induced uveitis in dogs. Am J Vet Res 50: 1877-1882

FICHMAN, RA 1996: Use of topical anesthesia alone in cataract surgery. J Cataract Refract Surg 22: 612-614

FINE, IH, MALONEY, WF, DILLMAN, DM 1993: Crack and flip phacoemulsification technique. J Cataract Refract Surg 19: 797-802

FISCHER, CA 1972: Lens-induced uveitis in dogs. J Am Anim Hosp Assoc 1: 39-48

GAIDDON, J, ROSOLEN, SG, LALLEMNET, PE, LEGARGASSOIN, JF 1997: New intraocular lens for dogs: the foldable cani 15S. Preliminary results of surgical technique. Invest Ophthalmol Vis Science 38 (suppl): 179

GAIDDON, J, ROSOLEN, SG, STERU, L, COOK, CS, PEIFFER, R jr. 1991: Use of biometry and keratometry for determining optimal power for intraocular lens implants in dogs. Am J Vet Res 52: 781-783

GAIDDON, J, ROSOLEN, SG, CROZAFON, P, STERU, D 1988: A new technique for lens extraction in surgery on dogs: endocapsular phaco-emulsification. Eur J Implant Refract Surg 6: 30-35

GILGER, BC 1997: Phacoemulsification technology and fundamentals. Vet Clin North Am: Small Anim Pract 27 : $1131-114$

GILGER, BC, WHITLEY, RD, MCLAUGHLIN, SA, WRIGHT, JC, BOOSINGER, TR 1993: Scanning electron microscopy of intraocular lenses that had been implanted in dogs. Am J Vet Res 54: 1183-1187

GILGER, BC, WHITLEY, RD, MCLAUGHLIN, SA, WRIGHT, JC, BOOSINGER, TR 1993: Clinicopathologic findings after experimental implantation of synthetic intraocular lenses in dogs. Am J Vet Res 54: 616-621

GIMBEL, HV 1991: Divide and conquer nucleofractis phacoemulsification: development and variations. J Cataract Refract Surg 17: 281-291

GIMBEL, HV, NEUHMAN, T 1990: Development, advantages and methods of the continuous circular capsulorhexis technique. J Cataract Refract Surg 16: 31-37

HLINOMAZOVÁ, Z, VLKOVÁ, E 2003: Uveitis anterior. In: Rozsíval P: Infections of the Eye. Grada Publishing s.r.o., pp. 127-148

KELMAN, CD 1967: Phacoemulsification and aspiration: a new technique of cataract removal. A preliminary report. Am J Ophthalmol 64: 23-35

KELMAN, CD 1994: The history and development of phacoemulsification. Int Ophthalmol Clin 34: 1-12

KOHNEN, T 1996: The variety of foldable intraocular lens material. J Cataract Refract Surg 22 (Suppl. 2): $1255-1257$

LINEBARGER, EJ, HARDTEN, MD, SHAH, GK, LINDSTROM, RL 1999: Phacoemulsification and modern cataract surgery. Surv Ophthalmol 44: 123-147

MAZZOCCO, TR 1984: Progress report: silicone IOLs. Cataract 1: 18-19

MCKOOL, RJ 1998: Phacochop has undergone refinements. Ocular Surger News Int 9: 8-11

MILLER, TR, WHITLEY, RD, MEEK, LA, GARCIA, GA, WILSON, MC, RAWLS, BH 1987: Phacofragmentation and aspiration for cataract extraction in dogs: 56 cases (1980-1984). J Am Vet Med Assoc 190: $1577-1580$

NASISSE, MP, DAVIDSON, MG: Surgery of the lens. In: Gelatt KN (ed): Veterinary ophthalmology, $2^{\text {nd }}$ ed, 1991. Lippincott Williams and Wilkins, pp. 827-856

NASISSE, MP, DAVIDSON, MG, JAMIESON, VE, ENGLISH, RV, OLIVERO, DK 1990: Phacoemulsification and intraocular lens implantation in dogs: a study of technique in 158 dogs. Prog Vet Comp Ophthalmol 1: $225-232$

NELMS, S, DAVIDSON, MG, NASISSE, MP 1994: Comparison of corneal and scleral surgical approaches for cataract extraction by phacoemulsification and intraocular lens implantation in normal dogs. Prog Vet Comp Ophthalmol 4: 53-60

OBSTBAUM, SA 1987: Intercapsular cataract microsurgery. J Cataract Refract Surg 13: 379

OSHIKA, T, SUZUKI, Y, KIZAKI, H, YAGUCHI, S 1996: Two year clinical study of a soft acrylic intraocular lens. J Cataract Refract Surg 22: 104-109

PAULSEN, ME, LAVACH, JD, SEVERIN, GA 1986: The effect of lens-induced uveitis on the success of extracapsular cataract extraction: a retrospective study of 65 lens removals in the dog. J Am Anim Hosp Assoc 22: $49-56$

RIDLEY, H 1952: Intraocular acrylic lenses. A recent development in the surgery of cataract. Br J Ophthalmol 36:113-122

ROOKS, RL, BRIGHTMAN, AH, MUSSELMAN, EE, HELPER, LC, MAGRANE, WG 1985: Extracapsular cataract extraction: an analysis of 240 operations in dogs. J Am Vet Med Assoc 187: 1013-1015

ROSOLEN, SG, personal communication, 2004

SHEPHERD, JR 1990: Insitu fracture. J Cataract Refract Surg 6: 436-440

STARTUP, FG 1967: Cataract surgery in the dog II. Published results. J Small Anim Pract 8: 671-674

STARTUP, FG 1967: Cataract surgery in dogs VI. Enzymatic zonulolysis. J Small Anim Pract 8: 689-691 
VAN DER WOERDT, A, NASISSE, MP, DAVIDSON, MG 1992: Lens-induced uveitis in dogs: 151 cases (19851992). J Am Vet Med Assoc 120: 921-926

VAN DER WOERDT, A, WILKIE, DA, MEYER, CW 1993: Ultrasonographic abnormalities in the eyes of dogs with cataracts: 147 cases (1986-1992). J Am Vet Med Assoc 203: 838-841

VLKOVÁ, E, HLINOMAZOVÁ, Z 2003: Infections of the Anterior Segment of the Eye. In: Rozsíval P: Infections of the Eye. Grada Publishing s.r.o., pp. 87-126

VLKOVÁ, E, HLINOMAZOVÁ, Z, PREISOVÁ, J 1991: Implantations of retropupilar intraocular lenses in posttraumatic conditions of the eye. Czech Ophthalmol 47: 105-110

WILLIAMS, DL, BOYDELL, IP, LONG, RD 1996: Current concepts in the management of canine cataracts: a survey of techniques used by surgeons in Britain, Europe and the USA and a review of recent literature. Vet Rec 138: 347-353 
Plate XIII

Kecová H. and Nečas A.: Phacoemulsification... pp. 85-92

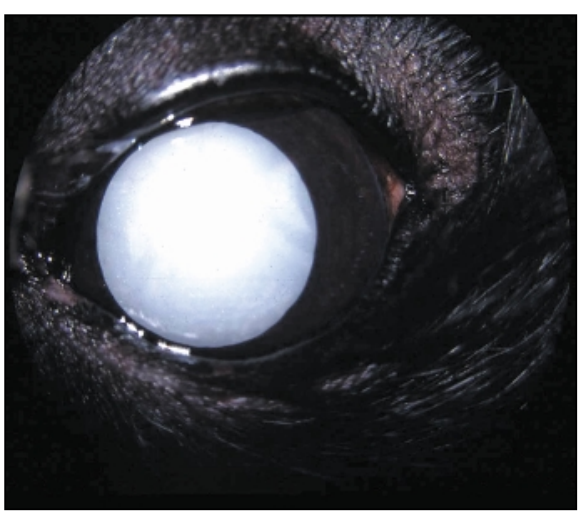

Fig. 1. Mature intumescent cataract in the dog.

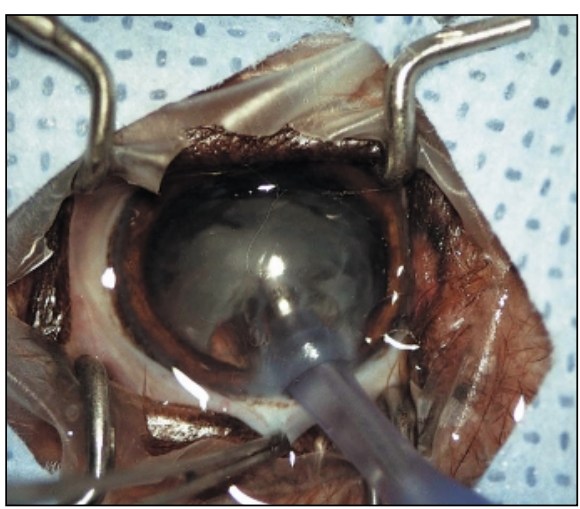

Fig. 2. Fragmentation, emulsification and aspiration of the nucleus.

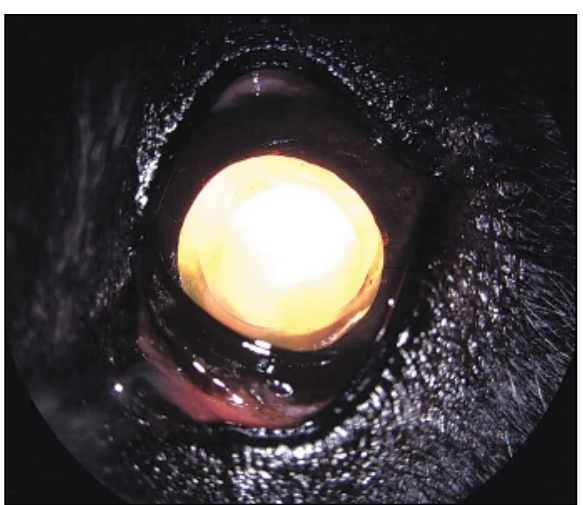

Fig. 3. Hydrophilic acrylic foldable IOL 3 months after implantation. 